\title{
Factors influencing the implementation of a hospital-wide intervention to promote professionalism and build a safety culture: A qualitative study
}

\author{
Lisa N. McKenzie, BPhysio (Hons), MHA; Louise Shaw, PhD, MPH, BSc (Hons) Physio; \\ Joanne E. Jordan, BA, BSc, MPH, PhD; Marliese Alexander, BPharm (Hons), MPH, PhD; \\ Mark O'Brien, MBBS, FRACGP, FACRRM, AFCHSM, GAICD; Sara J. Singer, MBA, \\ PhD; Elizabeth Manias, RN, BPharm, MPharm, MNStud, PhD, MPS, MSHPA
}

Lisa N. McKenzie, BPhysio(Hons), MHA, is Country Director, Australia and New Zealand, Institute for Healthcare Improvement, Boston. Louise Shaw, PhD, MPH, BSc (Hons) Physio, is Research Fellow, La Trobe University, Melbourne. Joanne E. Jordan, BA, BSc, MPH, $\mathrm{PhD}$, is Research Fellow, La Trobe University, Melbourne. Marliese Alexander, BPharm(Hons), MPH, PhD, is Research Fellow, La Trobe University, Melbourne. Mark O'Brien, MBBS, FRACGP, FACRRM, AFCHSM, GAICD, is Research Fellow, La Trobe University, Melbourne. Sara J. Singer, MBA, PhD, is Research Fellow, La Trobe University, Melbourne. Elizabeth Manias, RN, BPharm, MPharm, MNStud, PhD, MPS, MSHPA, is Research Fellow, La Trobe University, Melbourne. Please address correspondence to Lisa N. McKenzie, 1mckenzie@ihi.org.

\section{Abstract (word count: 250)}

Background: There is widespread recognition that creating a safety culture supports high quality healthcare. However, the complex factors impacting cultural change interventions are not well understood. This study examines factors influencing the implementation of an intervention to promote professionalism and build a safety culture at an Australian hospital.

Methods: The study was completed mid-way into the three-year intervention and involved collecting qualitative data from two sources. First, face-to-face interviews were conducted preand mid-intervention (18 months) with a purposely selected sample. Second, a survey with three open-ended questions was completed one-year into the intervention by clinical and patient support staff. Data from interviews and open-ended survey questions were analysed using a combination of inductive and deductive approaches.

Results: A total of 25 participants completed pre-intervention interviews and 24 took part midintervention. Of the 2,047 staff who completed the survey (61\% response rate), $59 \%$ of respondents answered at least one open-ended question. Multiple interrelated factors were identified as enhancing intervention implementation. These included leaders consistently demonstrating behaviours that support a safety culture, sustaining a favourable implementation climate, increasing the compatibility of working conditions with intervention aims, building confidence in professional accountability systems and remaining responsive to evolving needs.

Conclusions: Whilst strengthening safety culture remains a challenging endeavour, this study yields valuable insights into factors influencing implementation of a multi-faceted behaviour 
change intervention. The findings provide a basis for practical strategies that healthcare leaders seeking cultural improvements can employ to enhance the delivery of similar interventions and address potential impediments to success. 


\section{Introduction}

A strong safety culture is paramount in the pursuit of high quality and safe patient care [1-7]. Despite increased attention and investment, achieving desired cultural change remains an elusive goal [8-11]. Persistent safety failures and accounts of sub-optimal care continue to prompt healthcare leaders to rethink their approaches [12-15].

Leaders play a pivotal role in supporting cultural change and enabling a safety culture by motivating staff to choose behaviours that enhance safety $[10,16,17]$. However, efforts may be undermined if they allow unsafe or unprofessional behaviours to persist $[18,19]$. These behaviours can contribute to patient harm [2, 5, 6, 20-22], consumer dissatisfaction [23-25], medico-legal claims [26-29], and escalating healthcare costs [26, 28, 30-33]. Furthermore, they may adversely impact staff morale [34], turnover [34, 35] and team dynamics [20, 36]. To mitigate these outcomes, leaders increasingly recognise the need to encourage professionalism and tackle behaviours eroding safety culture [18, 19, 37, 38].

Evidence on the effectiveness of strategies to strengthen safety culture is emerging. Promising interventions incorporate components such as Leadership WalkRounds, multi-faceted unitbased programs, team training, and mechanisms to support team communication $[9,10,25,36$, 39]. Past research has primarily focused on assessing the impact of interventions, with less attention paid to factors that impede or enhance implementation. Additionally, a paucity of literature exists to evaluate interventions designed to reduce unprofessional behaviours that may impede cultural change in healthcare settings [18, 25, 40, 41]. Understanding more about the complex factors that influence intervention implementation is crucial to achieving sustained behaviour changes that strengthen safety culture. To help address this knowledge gap, this qualitative study aimed to examine factors influencing the implementation of an intervention to promote professionalism and build a safety culture at a major Australian tertiary hospital. This study formed part of a mid-way evaluation of the three-year organisation-wide intervention.

\section{Intervention}

The intervention explored in this study was referred to across the hospital as the 'Safety Culture Program' (the Program). The Program aimed to change staff ${ }^{1}$ behaviour to support a culture of safety and deliver more reliable healthcare, including:

- increasing the prevalence of professional and safe behaviours (e.g. speaking up for safety, encouraging teamwork or completing safety-related processes, such as practicing hand hygiene)

\footnotetext{
1 'Staff' includes both clinical (e.g. nurses, medical staff, allied health professionals, radiologists, pharmacists, clinical assistants and technicians) and non-clinical employees (e.g. management, administrators, as well as food, finance and environmental services staff).
} 
- reducing the prevalence of unprofessional and unsafe behaviours (e.g. disrespectful communication, intimidation, disruptive behaviour or working in a way that may reduce safety, such as failing to conduct patient risk assessments).

The intervention design was informed by an assessment of the hospital's safety climate using the validated Safety Attitudes Questionnaire (SAQ) [42] and a formal needs analysis. The findings from these sources indicated that many well-accepted practices, programs and systems that support a safety culture were in place across the hospital [9, 10, 43]. However, opportunities existed to more effectively address unprofessional behaviours, improve staff ability to communicate safety concerns and increase responsiveness to issues raised by frontline staff perceived to be impacting on safety culture. The Program consisted of multiple intervention components that responded to these findings (Table 1) and was implemented through a partnership between the hospital and the Cognitive Institute, an independent provider of healthcare education. The intervention encompassed some elements of the Cognitive Institute's Safety and Reliability Improvement Program [44], including an evidence-based intervention developed by Vanderbilt University Medical Centre (VUMC) [18, 25]. This was the first implementation of this intervention in Australia, with components adapted to address local contextual needs.

\section{Table 1. Intervention components implemented at the study site}

1. Delivered a multi-level education program on safety, reliability, communication skills and strategies to address unprofessional behaviour that may undermine a safety culture. This included mandatory 1 hour 'speaking up for safety' education sessions to teach staff how to respectfully raise safety concerns with colleagues using a graded assertiveness communication approach known as the Safety C.O.D.E. ${ }^{\mathrm{TM}}$ (Checks, Options, Demands, Elevates).

2. Implemented new professional accountability systems to more effectively identify, monitor and respond to unprofessional behaviour (using the adapted VUMC model) [18, 25]. This included:

- an online system ('weCare') to report unprofessional behaviours or recognise staff who demonstrate the organisation's values. Reporters can choose to remain anonymous.

- a graduated intervention process for addressing unprofessional staff behaviours (i.e. initially through informal peer-led conversations, and progressing to formal disciplinary procedures if behaviour persists).

3. Appointed accredited 'Safety Champions' to promote a safety culture and deliver 'speaking up for safety' education sessions.

4. Developed and implemented local action plans in each unit in response to results from a safety climate assessment survey (i.e. the Safety Attitudes Questionnaire) [42]. 


\section{Methodology}

\section{Study design}

To examine the factors influencing the Program's implementation, a qualitative exploratory design was employed using data from two sources. The first source was face-to-face semistructured interviews conducted pre- and mid-intervention (18 months). The second source was a survey with open-ended questions involving a cross-sectional cohort one year into the Program's implementation.

The study utilises best practice consolidated criteria for reporting qualitative research (COREQ) guidelines [45]. Study approval was granted by the hospital's Human Research Ethics Committee (QA2015129).

\section{Setting}

A multi-campus tertiary hospital in Melbourne, Australia with over 7,500 staff.

\section{Participants and sampling}

Face-to-face interviews

Staff employed for at least 12 months prior to the Program's commencement were eligible. This requirement increased the likelihood that participants would have awareness of contextual conditions potentially impacting the Program's implementation. Maximum variation sampling [46] was used to select staff directly involved in providing patient care ('sharp end') [46, 47] and encompassed a broad range of characteristics, including gender, length of service and profession. Criterion sampling [46] was used to select participants who represented the hospital management, consumer advisors and other staff overseeing the Program's implementation ('blunt end') [47].

\section{Open-ended survey questions}

All clinical and patient support staff at the hospital were invited to complete the organisationwide survey. Participation was voluntary and encouraged via emails, line managers, staff forums and newsletters.

\section{Data collection}

Face-to-face interviews

Semi-structured interviews were conducted face-to-face pre-intervention (February 2016) and mid-intervention (September 2017) by an independent and experienced qualitative researcher (JJ). Interview schedules were developed by a multi-disciplinary team, pilot tested with three content experts and refined accordingly to ensure clear understanding of questions. The onehour interviews explored views on the intervention's design, implementation process, contextual conditions impacting delivery, degree of staff support for the Program, and 
opportunities for improvement. All interviews were audio recorded after written consent was obtained.

\section{Open-ended survey questions}

The Safety Attitudes Questionnaire (SAQ) [42] was administered electronically by an external provider, Pascal Metrics, one year into the Program's implementation (March 2017). Three open-ended questions were included to obtain staff perspectives on the Program's implementation, particularly to elicit views on enhancing factors ('what is working'), limiting factors ('what is not working') and opportunities for improvement ('what can be done better'). All respondents remained anonymous.

\section{Data Analysis}

Interview recordings were transcribed verbatim and verified by participants. Open-ended survey responses were extracted from a secure electronic platform. NVIVO qualitative software (QSR International, Version 11, Cambridge, MA) was utilised to manage the analysis.

Analysis was undertaken in three stages reflecting the sequence of data collection and commencing with the pre-intervention interviews. An inductive approach, underpinned by grounded theory methods, was undertaken by one researcher to derive codes directly from preintervention data $[48,49]$. Key themes were developed through an iterative process of grouping codes into concepts, reviewing transcripts and further refining themes. A second researcher independently analysed a subset of the data (20\%) to confirm codes and themes. Results were discussed with minimal discrepancies identified.

The coding framework developed from the pre-intervention interviews was then used to analyse the open-ended questions (deductively). Where a new topic emerged from the data, this was inductively derived and the coding framework refined. The coding framework, derived from both the pre-intervention interviews and the open ended questions, were then used to deductively analyse the mid-intervention interviews. Similar to the second stage of analysis, where a new topic emerged, this was inductively derived and the coding framework was further refined. By utilising a combined inductive and deductive analytical approach, a comprehensive profile of the implementation issues experienced by staff over time was developed. Findings from all three stages were discussed, as was any discordance, and themes refined where necessary to reach consensus between the two researchers. 


\section{$\underline{\text { Results }}$}

A total of 25 participants completed the pre-intervention interviews, and 24 took part at midintervention, with 21 completing both interviews (Figure 1). Of the 2,047 staff who completed the survey (61\% response rate), 59\% of respondents (1,209 staff) answered at least one openended question (51\%, $47 \%$ and $46 \%$ respectively to each of the three questions). Sample sizes and demographic characteristics (Tables 2 and 3) were sufficient to ensure diversity in perspectives and achieve data saturation.

\section{Figure 1: Timeline of qualitative data sources}

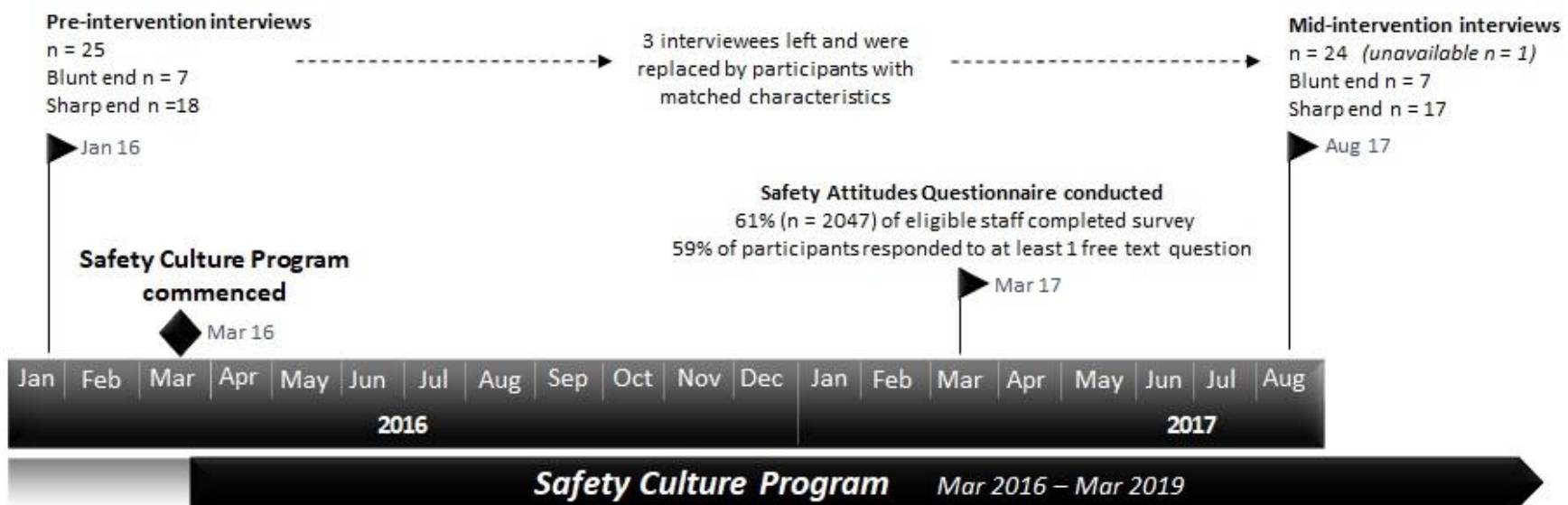

\section{Table 2. Characteristics of participants completing face-to-face interviews}

\begin{tabular}{|c|c|c|c|}
\hline & CHARACTERISTICS & $\begin{array}{c}\text { Pre-intervention } \\
\qquad \mathbf{n}=\mathbf{2 5} \\
\mathbf{n} \text { (\% of participants) }\end{array}$ & $\begin{array}{c}\text { Mid-intervention } \\
\mathbf{n}=\mathbf{2 4} \\
\mathbf{n} \text { (\% of participants) }\end{array}$ \\
\hline \multirow{4}{*}{ 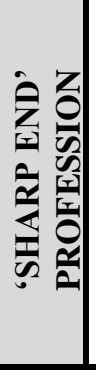 } & $\begin{array}{l}\text { Nurses } \\
\text { (Registered Nurse, Associate Nurse Manager, Nurse Manager) }\end{array}$ & $6(24 \%)$ & $6(25 \%)$ \\
\hline & $\begin{array}{l}\text { Medical staff } \\
\text { (Resident, Registrar, Consultant) }\end{array}$ & $4(16 \%)$ & $4(17 \%)$ \\
\hline & $\begin{array}{l}\text { Ancillary staff } \\
\text { (Pharmacist, Radiographer, Allied Health) }\end{array}$ & $4(16 \%)$ & $3(12 \%)$ \\
\hline & $\begin{array}{l}\text { Patient support staff } \\
\text { (Ward Clerk, Clinical Assistant, Food Services, Theatre Technician) }\end{array}$ & $4(16 \%)$ & $4(17 \%)$ \\
\hline \multirow{3}{*}{  } & $\begin{array}{l}\text { Senior leader } \\
\text { (Board Member, Executive, Director) }\end{array}$ & $3(12 \%)$ & $3(12 \%)$ \\
\hline & $\begin{array}{l}\text { Consumer advisors } \\
\text { (Members of the Consumer Advisory Committee) }\end{array}$ & $2(8 \%)$ & $2(8 \%)$ \\
\hline & $\begin{array}{l}\text { Safety Culture Program team members } \\
\text { (Staff responsible for Program implementation) }\end{array}$ & $2(8 \%)$ & $2(8 \%)$ \\
\hline \multirow{2}{*}{ 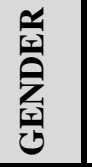 } & Female & $\mathbf{1 3}(52 \%)$ & $\mathbf{1 3}(54 \%)$ \\
\hline & Male & $12(48 \%)$ & $11(46 \%)$ \\
\hline \multirow{2}{*}{$\stackrel{\mathscr{2}}{9}$} & Length of Service $<5$ years & $13(52 \%)$ & $13(54 \%)$ \\
\hline & Length of Service $>5$ years & $12(48 \%)$ & $11(46 \%)$ \\
\hline
\end{tabular}




\begin{tabular}{|c|c|c|}
\hline & CHARACTERISTICS & $\begin{array}{c}1 \text { year into Program implementation } \\
\qquad \mathbf{n}=2047 \\
\mathbf{n} \text { (\% of participants) }\end{array}$ \\
\hline \multirow{4}{*}{ 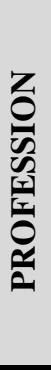 } & $\begin{array}{l}\text { Nurses } \\
\text { (Registered Nurse, Associate Nurse Manager, Nurse Manager) }\end{array}$ & $1223(60 \%)$ \\
\hline & $\begin{array}{l}\text { Medical staff } \\
\quad \text { (Resident, Registrar, Consultant) }\end{array}$ & $268(13 \%)$ \\
\hline & $\begin{array}{l}\text { Ancillary staff } \\
\text { (Pharmacist, Radiographer, Allied Health) }\end{array}$ & $324(16 \%)$ \\
\hline & $\begin{array}{l}\text { Patient support staff } \\
\text { (Ward Clerk, Clinical Assistant, Food Services, Theatre Technician) }\end{array}$ & $232(11 \%)$ \\
\hline \multirow{3}{*}{$\underset{\frac{\pi}{0}}{\stackrel{*}{*}}$} & Female & $1496(74 \%)$ \\
\hline & Male & $\mathbf{5 0 5}(25 \%)$ \\
\hline & Other & $9(1 \%)$ \\
\hline \multirow{2}{*}{$\stackrel{2}{9}$} & Length of service $<5$ years & $1003(49 \%)$ \\
\hline & Length of service $>5$ years & $1044(51 \%)$ \\
\hline
\end{tabular}

* The characteristics of all participants that completed the survey have been provided to maintain the anonymity of the sub-set responding to the open-text survey question. Survey respondents did not all identify their gender.

Analysis identified four major themes: implementation climate; compatibility with working conditions; leadership commitment; and intervention implementation processes (Table 4). Within each theme, factors 'enhancing' or 'limiting' the implementation of the Program were identified. Illustrative quotes have been provided with the subsequent brackets denoting the source; pre-intervention interviews (pre-int16), mid-intervention interviews (mid-int17) or open-ended survey questions (SAQ17). Minimal refinements were needed to the coding framework as a high degree of consistency was found between the themes identified in these 3 data sources. Emerging topics were mostly time-related and reflected the increased exposure study participants had to intervention components as the Program was implemented across the organisation.

\begin{tabular}{|l|l|l|}
\hline \multicolumn{2}{|c|}{ Table } & 4. Summary themes and sub-themes \\
\hline THEMES & \multicolumn{1}{c|}{ SUB-THEMES } \\
\hline $\begin{array}{l}\text { 1. Implementation } \\
\text { climate: Receptivity to } \\
\text { the Program, belief in } \\
\text { the case for change and } \\
\text { degree to which } \\
\begin{array}{l}\text { adoption of the } \\
\text { intervention is } \\
\text { supported }\end{array}\end{array}$ & $\begin{array}{l}\text { Creating the case for } \\
\text { change through } \\
\text { recognition of cultural } \\
\text { issues }\end{array}$ \\
\hline
\end{tabular}




\section{Table 4. Summary themes and sub-themes}

\begin{tabular}{|c|c|c|c|c|}
\hline \multirow{4}{*}{$\begin{array}{l}\text { THEMES } \\
\text { 2. Leadership } \\
\text { commitment: Degree } \\
\text { to which leaders appear } \\
\text { to engage, prioritise } \\
\text { and visibly support the } \\
\text { Program }\end{array}$} & \multicolumn{4}{|c|}{ SUB-THEMES } \\
\hline & \multicolumn{2}{|r|}{ Enhancing factor } & \multicolumn{2}{|r|}{ Limiting factor } \\
\hline & 2.1 & $\begin{array}{l}\text { Leaders' support for } \\
\text { Program implementation }\end{array}$ & 2.3 & $\begin{array}{l}\text { Some leaders not consistently } \\
\text { modelling desired behaviours }\end{array}$ \\
\hline & 2.2 & $\begin{array}{l}\text { Leaders holding staff } \\
\text { accountable for } \\
\text { unprofessional } \\
\text { behaviours }\end{array}$ & 2.4 & $\begin{array}{l}\text { Insufficient visibility or engagement } \\
\text { from senior managers to address local } \\
\text { issues }\end{array}$ \\
\hline $\begin{array}{l}\text { 3. Compatibility with } \\
\text { working conditions: } \\
\text { Alignment of Program } \\
\text { objectives with } \\
\text { contextual and } \\
\text { environmental factors } \\
\text { within the organisation }\end{array}$ & & & 3.1 & $\begin{array}{l}\text { Pressured environments and } \\
\text { demanding workloads misaligned } \\
\text { with Program aims } \\
\text { Perceptions of safety not always being } \\
\text { prioritised over other organisational } \\
\text { objectives }\end{array}$ \\
\hline \multirow{4}{*}{$\begin{array}{l}\text { 4. Intervention } \\
\text { implementation } \\
\text { process: Perspectives } \\
\text { on the implementation } \\
\text { process being used to } \\
\text { deliver the Program }\end{array}$} & \multirow[t]{4}{*}{4.1} & \multirow[t]{4}{*}{$\begin{array}{l}\text { Communications building } \\
\text { staff awareness }\end{array}$} & 4.2 & $\begin{array}{l}\text { Implementation issues reducing staff } \\
\text { confidence in the weCare system }\end{array}$ \\
\hline & & & 4.3 & $\begin{array}{l}\text { Inadequate reinforcement of key } \\
\text { messages and skills that support a } \\
\text { safety culture }\end{array}$ \\
\hline & & & 4.4 & $\begin{array}{l}\text { Program's implementation overly } \\
\text { focused on unprofessional behaviours }\end{array}$ \\
\hline & & & 4.5 & $\begin{array}{l}\text { Implementation predominately 'top- } \\
\text { down', rather than tailored to local } \\
\text { needs }\end{array}$ \\
\hline
\end{tabular}

\section{Implementation climate}

\subsection{Creating the case for change through recognition of cultural issues [Enhancing factor]}

Efforts to regularly raise awareness around the need for cultural change were perceived by study participants as having a positive influence on the organisation's implementation climate. Throughout the Program, Managers were observed increasing staff receptivity by acknowledging opportunities to improve culture and transparently reporting culture assessment findings (SAQ) in various forums.

"We had to get to the point where people recognised there's a problem. With a lot of these cultural issues...people just aren't aware of it occurring... What people are saying is 'normal behaviour' here is absolutely unacceptable... a mind shift has to take place." (Senior leader, pre-int16)

Furthermore, the Program's education and communications appeared to have broadened understanding around how unprofessional staff behaviour can undermine safety culture. These activities were viewed as enhancing implementation both at pre- and mid-intervention, with many participants sharing personal accounts of disruptive conduct. The Program also drew 
attention to cultural issues exacerbated by the organisation's "traditional hierarchical structure". Greater recognition of the adverse impacts associated with power differentials appeared to be a positive catalyst for change.

“They yell, swear...storm out...or sometimes they just ignore...people can't be proud of what they do when somebody senior dresses them down in front of everybody." (Nurse, pre-int16)

"If the surgeon is really anxious and tense, it flows down...they bully the anaesthetist, they bully the scrub nurse and scout nurses, and the techs cop it from everyone....sometimes it's just a perceived idea that some people are better than others. But when it comes to patient safety and safety of each other, everyone's input is valuable, it's not about hierarchies." (Patient support staff, pre-int16)

\subsection{Highlighting the importance of addressing unprofessional behaviours [Enhancing factor]}

Participants consistently acknowledged pre-intervention that not enough had been done to tackle unprofessional behaviours. These behaviours seemed to be accepted as part of someone's general demeanour or had remained unchecked as the individual was considered a "world-renowned leader". This was thought to have contributed to disruptive behaviours persisting, with some impressionable individuals emulating this conduct.

"the historical perceptions... [are]...there is a very large broom and there is a very large piece of carpet and everything is just swept under a rug." (Doctor, pre-int16)

"I refer to this as 'the health sausage machine'. These bright young things come in and want to change the world, and then a few years later come out as clones of their consultants and display those [disruptive] behaviours, because they've been accepted for a long, long time." (Manager, pre-int16)

Dissatisfaction around previous tolerance of unprofessional behaviours was creating a compelling case for change, with participants commending leaders for commencing the Program and "putting a line in the sand".

\section{Leadership commitment}

\subsection{Leaders' support for Program implementation [Enhancing factor]}

Leaders were considered crucial to supporting the Program's implementation. This support came from both leaders in management roles and informal leaders who did not hold positions of formal authority, however they were considered influential over groups of staff. Whilst several participants expressed scepticism pre-intervention around the level of investment that 
senior managers (Executives and Directors) would have in the Program, by mid-intervention they were reassured these leaders were committing time and resources to support cultural change.

"I see the potential for it to just become another tick box...If senior personnel...promote and encourage it, that will certainly have a positive impact... and vice versa, if there's not a lot of interest shown...then people under them are less likely to be engaged and see it as a valued program" (Ancillary staff, pre-int16)

"It's on the executive radar, it's one of their high priorities and it's terrific to know... and understand they're fully invested." (Nurse, mid-int17)

\subsection{Leaders holding staff accountable for unprofessional behaviours [Enhancing factor]}

Leaders, particularly in management roles, were perceived mid-intervention as enhancing the Program's implementation by redefining behavioural norms and increasing professional accountability. The prevailing view was that the Program signalled a new era of "zero tolerance", with these leaders addressing disruptive behaviours, regardless of the staff member's status or hierarchical level.

"There'll be some delicate politics... We're committed to taking whatever action we need to...we don't want to be sacking anybody, but we've got to be resolved to do what it takes." (Senior leader, pre-int16)

\subsection{Some leaders not consistently modelling desired behaviours [Limiting factor]}

Pre-intervention participants frequently stated that leaders must demonstrate behaviours that promote a safety culture because staff look to them for guidance on what conduct is acceptable. These behaviours were described as being "approachable", "respectful", "responsive to safety concerns", and "encouraging psychological safety".

"A hospital is the same as a family...kids look up to their parents and see what the behaviours are and...replicate those behaviours... I feel that the organisation looks up to our executive and sees behaviours that are being gotten away with. " (Senior Leader, pre-int16)

Despite leaders needing to demonstrate unwavering commitment to a safety culture, at midintervention several participants had observed leaders behaving in an unprofessional manner which was sending inconsistent messages and perceived as impeding implementation. 


\subsection{Insufficient visibility or engagement from senior managers to address local issues}

[Limiting factor]

A lack of visibility of senior managers was commonly viewed at pre- and mid-intervention as limiting the Program's delivery. Many frontline participants thought this contributed to leaders appearing disinterested in their day-to-day challenges and not adequately assisting to resolve local safety-related issues. Staff also believed this disconnect impacted on managers being able to understand what was really happening in patient care areas.

'There's no visibility...I receive emails from them, but Ifeel that there's a gap to getting out and walking the walk, talking the talk. Come around, see what's happening, talk about issues.' (Nurse, mid-int17)

\section{Compatibility with working conditions}

\subsection{Pressured environments and demanding workloads misaligned with Program aims} [Limiting factor]

Throughout the implementation, the hospital's environment and working conditions continued to be described as impeding the Program's delivery. Issues commonly identified included demanding workloads, bed shortages, ageing infrastructure, inaccessible equipment, and overreliance on paper rather than electronic medical records.

"I get what pressure does to people and we are in a pressured environment. We're always arguing about a dollar, we're always arguing about our environment, which is crumbling around our ears....we've got computers which would have worked on Noah's Ark." (Manager, pre-int16)

These challenging working conditions were perceived as incongruent with the Program aims, with participants raising concerns around them potentially compromising safety, team dynamics and staff morale.

"I feel undervalued and expected to work overtime to provide good care to my patients. I feel an increased risk of making errors that may be detrimental to patient safety because I am stressed and rushed... This hugely reduces my sense of job satisfaction." (Allied Health, SAQ17)

Furthermore, these pressures on staff were associated with Program components sometimes being considered additional tasks, rather than essential to safe care.

"I've got a hundred things to do today...I'm not going to have the time or the patience to go through my Safety C.O.D.E. ...I just get the bare minimum done... which might put safety or culture at risk." (Allied Health, mid-int17) 


\subsection{Perceptions of safety not always being prioritised over other organisational objectives}

\section{[Limiting factor]}

Participants described the challenges of giving safety precedence when also trying to respond to other organisational objectives, such as access demands and financial targets. When it appeared safety was not being prioritised, this was often viewed as conflicting with Program's intent and limiting implementation.

"Decisions are being made about patient care based on bed days and numbers, with a decreased attention to the patient's safety. People in positions of decision making are fearful of ramifications of not meeting targets... On multiple occasions over the past six months, they have been disrespectful and dismissive of staff when patient management and safety issues have been raised... Whilst I applaud the new safety system... the cultural change looks like it will take much longer." (Allied Health, SAQ17)

\section{Intervention implementation process}

\subsection{Communications generating staff awareness [Enhancing factor]}

Participants noted mid-intervention that formal communications promoting the Program were important in engaging staff in cultural change and demonstrating organisational commitment. Less feedback was provided about informal communications exchanged via day-to-day staff interactions, although several participants thought having respected internal 'Safety Champions' deliver education and disseminate key messages was enhancing implementation.

"The Program is well advertised, information about it is everywhere - posters, intranet page, computer screen savers. I think this helps provide a strong stance that this program and changing our culture is a priority." (Nurse, SAQ17).

Some interviewees expressed cynicism around the organisation sustaining these communications over three-years, particularly as the Program appeared less prominent over time.

"Everything sort of started with a big bang... and then there's been a bit of a vacuum since...it feels like it's lost momentum or it's moved off the agenda a little bit" (Ancillary staff, mid-int17).

\subsection{Implementation issues reducing staff confidence in the weCare system [Limiting factor]}

Pre-intervention, participants thought the professional accountability system, weCare, offered an accessible avenue for staff to request that confidential feedback be provided to those they felt were exhibiting unprofessional behaviours. However, at mid-intervention, a large proportion of participants identified process issues thought to be limiting implementation and decreasing staff confidence. These concerns included insufficient communication confirming action was taken in response to weCare reports and anonymous feedback increasing the 
potential for inappropriate use of the system. Despite some subjectivity in perceptions of unprofessional behaviour, a few staff described feeling distressed after receiving weCare feedback based on what they deemed vexatious and fictitious content. Whilst participants thought these accounts of apparent inappropriate weCare usage needed to be addressed, they also acknowledged that maintaining anonymity may allay fears of reports leading to "resentment, retribution or career suicide" (Nurse, mid-int17).

"There's no feedback loop to the person that's reported...so there is this period of time where the behaviour still continues and people lose faith that something's happening." (Nurse, mid-int17)

"With this anonymous dobber ${ }^{2}$ line...my concern is the majority of people will report someone who they think has been mean to them. It won't actually end up being Dr Suchand-Such, who I like... who never washes their hands." (Doctor, mid-int17)

\subsection{Inadequate reinforcement of key messages and skills that support a safety culture [Limiting factor]}

Participants affirmed the value of the Program's education component, however, they frequently described the mandatory one-hour 'speaking up for safety' workshop as insufficient to enable staff to confidently translate these skills back into their work setting. Whilst this education provided "common terminology" to respectfully raise safety concerns, the consensus at mid-intervention was that the Program's implementation needed to include additional education sessions to consolidate skills and initiatives to embed safety language in daily practice.

'The Speaking Up For Safety seminar is quite powerful and uplifting... but a one-hour session ... in three months' time...is a struggle to remember. Obviously it's not the specifics that matter...but it's not quite having the lasting effect that may be required." (Doctor, mid-int17)

\subsection{Program's implementation overly focused on unprofessional behaviours [Limiting factor]}

Mid-intervention participants perceived the weCare system and 'speaking up' education as skewing the focus towards a small number of staff who behave unprofessionally. Several participants believed implementation could be improved with greater acknowledgement of staff demonstrating desirable behaviours and learning from high-performing teams with positive cultural dynamics.

\footnotetext{
${ }^{2}$ A "dobber" is a colloquial Australian term for 'a person who secretly tells someone in authority that someone else has done something wrong' [50]
} 
"We may be able to do more to positively encourage the abundance of examples of high quality work and communication...My concern is the Program may...lose its effectiveness if there is insufficient attention to examples of positive behaviour and good outcomes" (Nurse, SAQ17).

\subsection{Implementation predominately 'top-down', rather than tailored to local needs [Limiting factor]}

The Program's implementation was commonly viewed as being 'top-down' and not adequately reflecting the unique needs of unit-level sub-cultures.

"I feel that the staff aren't really connected with the organisational program because it kind of sits up here and it's very disconnected from what goes on at grassroots level" (Nurse, mid-int17)

At pre-intervention, some interviewees were hopeful the local action plans developed in response to culture assessment findings (SAQ) would help to address frontline issues. However, at mid-intervention, most participants were not aware of these action plans, or described them as "a waste of time" and "just another administrative burden" (Nurse, midint17). Many interviewees thought greater efforts were needed to engage frontline staff to ensure the Program was addressing concerns of importance to them.

\section{$\underline{\text { Discussion }}$}

This study identified important factors influencing the implementation of an intervention to increase professionalism and build a safety culture. Whilst achieving cultural improvements remains an enduring challenge [8-11], our findings are formative and practical for healthcare leaders aiming to elicit positive behaviour changes. The study results were developed into strategies designed to enhance implementation (Table 5) and inform ongoing intervention refinements over the final phase of the three-year Program. Strategies include creating an implementation climate to increase staff receptivity to the intervention, ensuring leaders consistently model behaviours that promote a safety culture, increasing the compatibility of working conditions with intervention aims, tailoring implementation to respond to evolving local needs and building confidence in systems to reduce unprofessional behaviours. These strategies, and the candid observations underpinning them, are also pertinent to organisations embarking on similar cultural change journeys. 


\section{Table 5. Strategies derived from this study to enhance intervention implementation}

1. Implementation climate: continuously build the case for change

- Periodically conduct culture assessments, identify improvement opportunities and transparently report findings

- Increase awareness of unprofessional behaviours and the associated adverse impacts

- Promote the benefits of a safety culture and adopt a 'zero tolerance' approach to behaviours that may undermine these efforts

\section{Leadership commitment: model behaviours that support a safety culture}

- Ensure leaders are visible and consistently model desirable behaviours including:

$\circ$ foster environments of respect, trust and psychological safety

$\circ$ promote clear behavioural expectations and demonstrate unwavering commitment to addressing unprofessional behaviours

o regularly engage with and assist frontline staff to address local safety-related concerns

o support intervention implementation (including allocating appropriate resources)

3. Compatibility with working conditions: increase alignment with Program objectives

- Acknowledge and where possible, address working conditions perceived as incongruent with a safety culture

- Ensure safety is prioritised over other organisational objectives

4. Intervention implementation process: avoid a one-size-fits-all approach

- Tailor intervention implementation at the unit-level and engage frontline staff in the process to ensure it addresses local contexts

- Provide sufficient education to equip staff with skills that support a safety culture (e.g. 'speaking up for safety')

- Build confidence in systems used to identify, monitor and address unprofessional behaviour (including resolving implementation issues)

- Deliver engaging communications throughout implementation and consider appointing 'Champions' to disseminate key messages that support cultural change

- Avoid intervention implementation becoming overly focused on unprofessional behaviours and acknowledge desirable behaviours demonstrated by the majority of staff

- Evaluate the intervention and modify implementation in response to evolving needs

The four major themes identified as influencing the Program's delivery (Table 4) had a high degree of concordance with those commonly cited in implementation science literature (inner organisational setting, characteristics of individuals/professionals, intervention characteristics and process) [51, 52]. In contrast to prevailing implementation science themes, our study did not identify the outer setting as having a notable influence. This was interesting given substantial contemporaneous external pressures from local and national organisations calling on health services to tackle concerning rates of unprofessional behaviours [53-56]. These findings suggest successful implementation may be more dependent on internal rather than external influences. To create this internal tension for change, our study suggests multimodal communications delivered by leaders and reinforced by 'Safety Champions' may increase staff receptivity, although sustainability was identified as a challenge. 
Our study lends weight to the crucial influence of leaders on intervention implementation, particularly in promoting professional accountability [18, 19, 37]. Given past perceptions of unprofessional behaviours sometimes remaining unchecked, it was clear the Program signalled change with leaders declaring a 'zero tolerance' approach. Our findings suggest successful implementation is contingent on leaders consistently demonstrating their commitment to safety and professionalism. It was therefore difficult to ascertain why some leaders occasionally behaved in a manner that appeared misaligned with these intentions. Potentially, these leaders may have been unaware of behavioural inconsistencies, particularly as the evidence shows their perceptions of culture are often more favourable than those reported by frontline staff [57-59]. Given their significant influence, our findings suggest it is important to invest in specific training for leaders to build their understanding of organisational cultural problems and to establish systems that provide them with regular feedback to encourage desirable behaviours $[60,61]$. Additionally, our study emphasises the benefits of leaders regularly connecting with frontline staff and supporting them to address safety-related concerns perceived as incongruent with Program aims $[62,63]$. Whilst some of these concerns seemed intractable and ubiquitous in nature (demanding workloads and bed shortages), there are multiple reasons why these visible day-to-day interactions can support Program implementation. Firstly, it shows leaders are prioritising the removal of barriers to safe care [16, 64]. Secondly, staff who observe leaders improving safety may be encouraged to follow suit [16, 64, 65]. Finally, these interactions provide an opportunity to build respect across hierarchical levels [66] and promote psychological safety where staff feel comfortable speaking up [67, 68]. Collectively, these actions can facilitate cultural change and achieve greater compatibility with intervention aims through delivering tangible improvements in working conditions.[16, 64].

There were multiple intervention components designed to increase professionalism and reduce behaviours that can undermine a safety culture. The education component was perceived as valuable, particularly to improve skills when communicating and addressing behaviours causing safety concerns. Our findings indicate that one-off education may not equip staff with the necessary skills to translate knowledge into practice, which also accords with previous studies [69-71]. To effectively 'speak up for safety' back in their work settings and utilise the Program's graded assertiveness communication approach, our study suggests strategies that support the consolidation of these skills would be beneficial. For situations when staff feel unable to 'speak up for safety' directly to a colleague, the new professional accountability system, weCare, was providing an alternate option for raising these concerns. However, issues associated weCare's implementation appeared to be hampering staff use of the system. Whilst views were divided on whether the positives outweighed the negatives associated with anonymous reporting, we found some staff needed reassurance of the system's integrity. To mitigate system concerns raised in our study, it was deemed useful to provide regular deidentified data confirming appropriate responses had been taken to staff reports and to highlight the system's safeguards to abate inappropriate usage. Although evidence is emerging on the benefits of professional accountability systems [18, 19, 37-39, 41, 72, 73], our study suggests effective implementation relies on staff having confidence in these systems. 
Whilst professional accountability was a prominent focus in this intervention, the literature confirms that usually only a minority of staff display unprofessional behaviours (i.e. approximately $<5 \%)[18,32,73,74]$. Accordingly, our findings indicate that leaders should 'tend to the whole orchard', rather than just the few 'bad apples'. This can be achieved by tailoring intervention implementation to the varied staff behaviours and subcultures commonly present within an organisation [75-78]. Leaders can consider strategies such as recognising staff who behave professionally, foster teamwork, and consistently demonstrate safe practices [41]. Opting for a balanced approach that also leverages staff strengths may increase engagement [79] and accelerate the spread of positive behaviours.

\section{$\underline{\text { Strengths and limitations }}$}

Key strengths of our study include the multimodal approach used to gather longitudinal data [80] (interviews and open-ended survey), coupled with the high participation rates. This enabled extensive data to be collected from diverse participants which enhanced the validity of findings and achieved triangulation of emergent themes. To our knowledge, this is the only qualitative study to systematically examine factors influencing the implementation of a Program incorporating elements of the VUMC intervention $[18,25]$. It is also the first time that these factors have been explored in an Australian context, with previous research predominately conducted in the USA $[18,19,37,38]$.

Our results should be interpreted in light of some limitations. Participants' perspectives may not be representative of all those impacted by the Program. Whilst these views appeared to be expressed with candour, it is difficult to determine the extent of biases, such as participants providing socially desirable responses. The generalisability of findings is unclear as the study was conducted at a single hospital and focused on a specific intervention program. Additional research is needed into the factors influencing the effectiveness of behaviour change interventions that focus on building a culture of safety and professionalism. This includes researching the complex interactions between the design, implementation, contextual conditions and impact of these cultural change interventions. 


\section{Conclusion}

Culture is a powerful lever for increasing the safety and quality of healthcare. However, changing 'the way we do things around here' and demonstrating 'zero tolerance' to behaviours that can erode a safety culture remains a daunting challenge. Drawing on frank feedback, this study broadens our understanding of multiple, interrelated factors influencing implementation and consequently the effectiveness of such behaviour change interventions. The findings suggest leaders were highly influential over implementation, with our study highlighting a need for steadfast commitment to both safety and professionalism. To demonstrate this commitment, leaders can consistently model desirable behaviours and support frontline teams to resolve safety-related concerns that increase the intervention's compatibility with working conditions. It was also considered important to create a favourable implementation climate and remain responsive to staff feedback pertinent to the intervention. This included sustaining communications and education throughout the program, particularly to enable staff to effectively 'speak up for safety' and have confidence in professional accountability systems. Without an appreciation of these factors, healthcare leaders pursuing a safety culture may encounter similar impediments to behaviour change as those of their predecessors. By considering how these findings translate to their specific organisational contexts, leaders stand a better chance of designing and delivering cultural improvements that endure.

\section{$\underline{\text { Acknowledgments }}$}

The authors thank the hospital's leadership team and staff for their support and participation in this research. We particularly want to acknowledge their engagement in the study process and candour when sharing views on the Safety Culture Program. The authors greatly appreciated the assistance provided by Varnia Muys and Nina Bianco throughout the study, including their useful feedback on earlier drafts of this manuscript. We would also like to express our gratitude to Käri Greene for her valuable advice on the study design and qualitative methods. 


\section{References}

1. Braithwaite, J., et al. Association between organisational and workplace cultures, and patient outcomes: systematic review. BMJ Open, 2017. 7, DOI: ARTN e01770810.1136/bmjopen2017-017708.

2. Berry, J.C., et al. Improved Safety Culture and Teamwork Climate Are Associated With Decreases in Patient Harm and Hospital Mortality Across a Hospital System. J Patient Saf, 2016. DOI: 10.1097/PTS.0000000000000251.

3. Weaver, S.J., et al., On the CUSP: Stop BSI: evaluating the relationship between central lineassociated bloodstream infection rate and patient safety climate profile. Am J Infect Control, 2014. 42 (10 Suppl): p. S203-8.

4. Hansen, L.O., M.V. Williams, and S.J. Singer, Perceptions of hospital safety climate and incidence of readmission. Health Serv Res, 2011. 46(2): p. 596-616.

5. Fan, C.J., et al., Association of Safety Culture with Surgical Site Infection Outcomes. J Am Coll Surg, 2016. 222(2): p. 122-8.

6. Mardon, R.E., et al., Exploring relationships between hospital patient safety culture and adverse events. J Patient Saf, 2010. 6(4): p. 226-32.

7. Sorra, J., et al., Exploring relationships between patient safety culture and patients' assessments of hospital care. J Patient Saf, 2012. 8(3): p. 131-9.

8. National Patient Safety Foundation, Free from Harm: Accelerating Patient Safety Improvement Fifteen Years after to Err is Human. 2015, National Patient Safety Foundation: Boston, MA.

9. Morello, R.T., et al., Strategies for improving patient safety culture in hospitals: a systematic review. BMJ Qual Saf, 2013. 22(1): p. 11-8.

10. Weaver, S.J., et al., Promoting a culture of safety as a patient safety strategy: a systematic review. Ann Intern Med, 2013. 158(5 Pt 2): p. 369-74.

11. Kohn, L.T., J.M. Corrigan, and M.S. Donaldson, To err is human: building a safer health system. A report of the Committee on Quality of Health Care in America, Institute of Medicine. 2000, Washington, DC: National Academy Press.

12. Landrigan, C.P., et al., Temporal trends in rates of patient harm resulting from medical care. $\mathrm{N}$ Engl J Med, 2010. 363(22): p. 2124-34.

13. Chassin, M.R., Improving the quality of health care: what's taking so long? Health Aff (Millwood), 2013. 32(10): p. 1761-5.

14. Classen, D.C., et al., 'Global trigger tool' shows that adverse events in hospitals may be ten times greater than previously measured. Health Aff (Millwood), 2011. 30(4): p. 581-9.

15. James, J.T., A new, evidence-based estimate of patient harms associated with hospital care. J Patient Saf, 2013. 9(3): p. 122-8.

16. Singer, S.J. and T.J. Vogus, Reducing Hospital Errors: Interventions that Build Safety Culture. Annual Review of Public Health, Vol 34, 2013. 34: p. 373-96.

17. Zohar, D. and G. Luria, Climate as a social-cognitive construction of supervisory safety practices: Scripts as proxy of behavior patterns. Journal of Applied Psychology, 2004. 89(2): p. 322-333.

18. Webb, L.E., et al., Using Coworker Observations to Promote Accountability for Disrespectful and Unsafe Behaviors by Physicians and Advanced Practice Professionals. Joint Commission Journal on Quality and Patient Safety, 2016. 42(4): p. 149-61.

19. Hickson, G.B., et al., Balancing systems and individual accountability in a safety culture, in From Front Office to Front Line: Essential Issues for Health Care Leaders. 2012, Joint Commission Resources: Oakbrook Terrace, IL, USA. p. 1-37.

20. Rosenstein, A.H. and M. O'Daniel, A survey of the impact of disruptive behaviors and communication defects on patient safety. Jt Comm J Qual Patient Saf, 2008. 34(8): p. 464-71.

21. Singer, S., et al., Relationship of safety climate and safety performance in hospitals. Health Serv Res, 2009. 44(2 Pt 1): p. 399-421. 
22. Cooper, W.O., et al., Use of Unsolicited Patient Observations to Identify Surgeons With Increased Risk for Postoperative Complications. Jama Surgery, 2017. 152(6): p. 522-529.

23. Blanchard, J. and N. Lurie, R-E-S-P-E-C-T: patient reports of disrespect in the health care setting and its impact on care. J Fam Pract, 2004. 53(9): p. 721-30.

24. Lee, A.V., et al., What can we learn from patient dissatisfaction? An analysis of dissatisfying events at an academic medical center. Journal of hospital medicine, 2010. 5(9): p. 514-520.

25. Hickson, G.B., et al., A complementary approach to promoting professionalism: identifying, measuring, and addressing unprofessional behaviors. Acad Med, 2007. 82(11): p. 1040-8.

26. Hickson, G.B. and S.S. Entman, Physician practice behavior and litigation risk: evidence and opportunity. Clin Obstet Gynecol, 2008. 51(4): p. 688-99.

27. Hickson, G.B. and S.S. Entman, Physicians influence and the malpractice problem. Obstet Gynecol, 2010. 115(4): p. 682-6.

28. Hickson, G.B., et al., Patient complaints and malpractice risk in a regional healthcare center. South Med J, 2007. 100(8): p. 791-6.

29. Stelfox, H.T., et al., The relation of patient satisfaction with complaints against physicians and malpractice lawsuits. Am J Med, 2005. 118(10): p. 1126-33.

30. Hickson, G.B., et al., Patient complaints and malpractice risk. JAMA, 2002. 287(22): p. 2951-7.

31. Catron, T.F., et al., Patient Complaints and Adverse Surgical Outcomes. Am J Med Qual, 2016. 31(5): p. 415-22.

32. Stewart, K., R. Wyatt, and J. Conway, Unprofessional behaviour and patient safety. International Journal of Clinical Leadership, 2011. 17(2): p. 93-101.

33. Rosenstein, A.H., The quality and economic impact of disruptive behaviors on clinical outcomes of patient care. Am J Med Qual, 2011. 26(5): p. 372-9.

34. Rosenstein, A.H., Original research: nurse-physician relationships: impact on nurse satisfaction and retention. Am J Nurs, 2002. 102(6): p. 26-34.

35. Rosenstein, A.H., H. Russell, and R. Lauve, Disruptive physician behavior contributes to nursing shortage. Study links bad behavior by doctors to nurses leaving the profession. Physician Exec, 2002. 28(6): p. 8-11.

36. Rosenstein, A.H. and M. O'Daniel, Impact and implications of disruptive behavior in the perioperative arena. J Am Coll Surg, 2006. 203(1): p. 96-105.

37. Shapiro, J., A. Whittemore, and L.C. Tsen, Instituting a culture of professionalism: the establishment of a center for professionalism and peer support. Jt Comm J Qual Patient Saf, 2014. 40(4): p. 168-77.

38. Rosenstein, A.H., Managing disruptive behaviors in the health care setting: focus on obstetrics services. Am J Obstet Gynecol, 2011. 204(3): p. 187-92.

39. Hickson, G.B. and A.D. Jenkins, Identifying and addressing communication failures as a means of reducing unnecessary malpractice claims. N C Med J, 2007. 68(5): p. 362-4.

40. Gillen, P.A., et al., Interventions for prevention of bullying in the workplace. Cochrane Database of Systematic Reviews, 2017(1).

41. Rosenstein, A.H., Physician disruptive behaviors: Five year progress report. World J Clin Cases, 2015. 3(11): p. 930-4.

42. Sexton, J.B., et al. The Safety Attitudes Questionnaire: psychometric properties, benchmarking data, and emerging research. BMC Health Serv Res, 2006. 6, 44 DOI: 10.1186/1472-6963-644.

43. Campione, J. and T. Famolaro, Promising Practices for Improving Hospital Patient Safety Culture. Jt Comm J Qual Patient Saf, 2018. 44(1): p. 23-32.

44. Cognitive Institute: Safety and Reliability Improvement Program. [cited 201820 May]; Available from: http://www.cognitiveinstitute.org/our-partners/.

45. Tong, A., P. Sainsbury, and J. Craig, Consolidated criteria for reporting qualitative research (COREQ): a 32-item checklist for interviews and focus groups. Int J Qual Health Care, 2007. 19(6): p. 349-57. 
46. Patton, M.Q., Qualitative Research \& Evaluation Methods: Integrating Theory and Practice 4th ed. 2014, London, UK: Sage Publications.

47. Woods, D.D., et al., Behind human error. 2nd ed. 2010, London, UK: CRC Press.

48. Charmaz, K., Grounded theory: A practical guide through qualitative analysis. 2006, London, UK: Sage Publications.

49. Corbin, J.M. and A. Strauss, Basics of qualitative research: Techniques and Procedures for Developing Grounded Theory. 4th ed. 2015, London, UK: Sage Publications.

50. Cambridge Dictionary. 2019 [cited 20194 April]; Available from: https://dictionary.cambridge.org/dictionary/english/dobber.

51. Lau, R., et al., Achieving change in primary care-causes of the evidence to practice gap: systematic reviews of reviews. Implementation Science, 2016. 11(1): p. 40.

52. Damschroder, L.J., et al. Fostering implementation of health services research findings into practice: a consolidated framework for advancing implementation science. Implement Sci, 2009. 4, 50 DOI: 10.1186/1748-5908-4-50.

53. Victorian Auditor-General. Bullying and harassment in the health sector: Victorian AuditorGeneral's report. 2016; Available from:

https://www.parliament.vic.gov.au/file uploads/20160323-Bullying G5h4gaMC.pdf.

54. Medical complaints process in Australia. Senate Standing Committee on Community Affairs 2016; Available from:

http://www.aph.gov.au/Parliamentary Business/Committees/Senate/CommunityAffairs/Me dical Complaints.

55. Royal Australasian College of Surgeons. Expert Advisory Group advising the Royal Australasian College of Surgeons: discrimination, bullying and sexual harassment prevalence survey. . 2015 [cited 201721 June]; Available from:

https://surgeons.org/media/22045682/PrevalenceSurvey Summary-of-Facts FINAL.pdf.

56. Australasian College for Emergency Medicine. ACEM to tackle bullying and harassment. 2017; Available from: https://acem.org.au/News/Aug-2017/ACEM-to-tackle-bullying-andharassment.

57. Singer, S.J., et al., Patient safety climate in US hospitals: variation by management level. Med Care, 2008. 46(11): p. 1149-56.

58. Pronovost, P.J., et al., Evaluation of the culture of safety: survey of clinicians and managers in an academic medical center. Qual Saf Health Care, 2003. 12(6): p. 405-10.

59. Hartmann, C.W., et al., An overview of patient safety climate in the VA. Health Serv Res, 2008. 43(4): p. 1263-84.

60. Zohar, D., Modifying supervisory practices to improve subunit safety: a leadership-based intervention model. J Appl Psychol, 2002. 87(1): p. 156-63.

61. Zohar, D. and G. Luria, The use of supervisory practices as leverage to improve safety behavior: A cross-level intervention model. Journal of Safety Research, 2003. 34(5): p. 567577.

62. Frankel, A., et al., Patient safety leadership WalkRounds ${ }^{\text {TM }}$. Joint Commission Journal on Quality and Patient Safety, 2003. 29(1): p. 16-26.

63. Frankel, A., et al., Patient safety leadership WalkRounds ${ }^{T m}$ at Partners Healthcare: Learning from implementation. Joint Commission journal on quality and patient safety, 2005. 31(8): p. 423-437.

64. Vogus, T.J., K.M. Sutcliffe, and K.E. Weick, Doing No Harm: Enabling, Enacting, and Elaborating a Culture of Safety in Health Care. Academy of Management Perspectives, 2010. 24(4): p. 60-77.

65. Singer, S.J. Our maturing understanding of safety culture: how to change it and how it changes safety. Patient Safety Network 2017 [cited 2017 16th Aug]; Available from: https://psnet.ahrq.gov/perspectives/perspective/220. 
66. Singer, S.J. and A.L. Tucker, The evolving literature on safety WalkRounds: emerging themes and practical messages. BMJ Qual Saf, 2014. 23(10): p. 789-800.

67. Edmondson, A.C., Teaming: How organizations learn, innovate, and compete in the knowledge economy. 2012, San Francisco, CA, USA: John Wiley \& Sons.

68. Edmondson, A.C., Managing the Risk of Learning: Psychological Safety in Work Teams, in International Handbook of Organizational Teamwork and Cooperative Working. 2003. p. 25577.

69. Law, B.Y. and E.A. Chan, The experience of learning to speak up: a narrative inquiry on newly graduated registered nurses. J Clin Nurs, 2015. 24(13-14): p. 1837-48.

70. Ulrich, B. and T. Kear, Patient Safety Culture in Nephrology Nurse Practice Settings: Initial Findings. Nephrol Nurs J, 2014. 41(5): p. 459-75.

71. Bowman, C., N. Neeman, and N.L. Sehgal, Enculturation of unsafe attitudes and behaviors: student perceptions of safety culture. Acad Med, 2013. 88(6): p. 802-10.

72. Dupree, E., et al., Professionalism: a necessary ingredient in a culture of safety. Jt Comm J Qual Patient Saf, 2011. 37(10): p. 447-55.

73. Pichert, J.W., et al., An intervention model that promotes accountability: peer messengers and patient/family complaints. Jt Comm J Qual Patient Saf, 2013. 39(10): p. 435-46.

74. Rosenstein, A.H. and M. O'Daniel, Invited article: Managing disruptive physician behavior: impact on staff relationships and patient care. Neurology, 2008. 70(17): p. 1564-70.

75. Campbell, E.G., et al., Patient safety climate in hospitals: act locally on variation across units. Jt Comm J Qual Patient Saf, 2010. 36(7): p. 319-26.

76. Singer, S.J., et al., Patient safety climate in 92 US hospitals: differences by work area and discipline. Med Care, 2009. 47(1): p. 23-31.

77. Huang, D.T., et al., Intensive care unit safety culture and outcomes: a US multicenter study. Int J Qual Health Care, 2010. 22(3): p. 151-61.

78. Schwendimann, R., et al., Variation in safety culture dimensions within and between US and Swiss Hospital Units: an exploratory study. BMJ Qual Saf, 2013. 22(1): p. 32-41.

79. Rath, T. and B. Conchie, Strengths based leadership: Great leaders, teams, and why people follow. 2008, New York, USA: Gallup Press.

80. Solomon, P., et al., Two approaches to longitudinal qualitative analyses in rehabilitation and disability research. 2019. 1-7. 